quantities of levan from such sugars, even where it had been added.

By adopting special methods, however, a separation of the levan from inoculated sugars was affected, thus bringing the deterioration process of sugar's in line with that found to take place in sugar solutions. For this work inoculated Peruvian crystals were used. Two solutions of I4 per cent. sugar of 5 liters each were thoroughly sterilized, and then inciculated with yeast and allowed to ferment. When most of the sugar had fermented, the solutions were filtered and evaporated to I liter. The gum was precipitated from the concentrate by adding 3 liters of alcohol made alkaline with sodium hydroxide. After the gum had been dissolved and precipitated four times, a small quantity was obtained which was polarized, hydrolyzed, and the resulting levulose polarized:

\begin{tabular}{|c|c|c|c|}
\hline & No. I. & No. II. & $\begin{array}{c}\text { Control } \\
99.8 \\
\text { sugar. }\end{array}$ \\
\hline Polarization of gurn $\ldots \ldots \ldots \ldots \ldots$ & -0.35 & -10.24 & 00.0 \\
\hline Polarization of hydrolyzed product & -0.72 & -10.51 & 00.0 \\
\hline Theoretical polarization............. & -0.78 & 一) .53 & 00.0 \\
\hline
\end{tabular}

Attempts have been made to find a means of avoiding the error in analysis which is caused by the presence of levan. The invertase method was tried and found unsatisfactory, and likewise the Andrlik urea method. In making the direct polarimetric reading in acid and urea solutions it was found that the rate at which the gum hydrolyzed was slower than the rate of sucrose inversion.

\section{THE DETECTION OF SUBSTITUTION OF SPIRITS FOR AGED WHISKEY. A DISCUSSION OF THE CHEMICAL DATA PRESENTED IN THE TRIAL OF U.S. vs. NINE BARRELS OF WHISKEY.}

By A. B. ADAMs, Chief Chemist, Internal Revenide Bureau, Received April 24, 1911

In this country when it is intended to age new whiskey, it is, as a rule, placed in Government Bonded Warehouses for the purpose. When it enters the warehouse it is stamped with what is called the "warehouse stamp" which bears the date of inspection and gauge. When the owner desires to withdraw the package, the tax is paid and a tax-paid stamp placed upon the stamp head, denoting the fact, stating also the time of tax payment and number of gallons content. This is called a "double stamped package."

The integrity of the stamp and the Government marks and brands is guaranteed by law, or rather, the Statutes provide a heavy fine and imprisonment for changing the contents of a package, unless the marks and brands are destroyed.

For many years it has been a common custom among certain dealers to take such a double stamped package, dispase of a portion, or all of its contents, and then refill the package with either an inferior grade of whiskey or alcohol diluted to the proper proof and artificially colored and flavored. This is a violation, as stated above, of Section 3455 R.S.

The past several years the Commissioner of Internal Revenue has claimed that the substitution of

${ }_{1}$ Published by authority of the Commissioner of Internal Revenue. other spirits in a double stamped package could be ascertained by chemical examination. This claim was vigorously disputed by the attorneys who represented the Wholesale Liquor Dealers' Association before the Bureau of Internal Revenue, it being claimed by them that packages of whiskey varied too much from one another in their chemical constituents to make such a comparison reliable.

At their request it was arranged that a case be tried before a jury, and from the many packages under seizure thirteen barrels were selected for trial. These had been seized on the premises of - - Wholesale Liquor Dealers, Cincinnati.

As four of the packages were libeled later than the others they became two cases, namely, "U. S. ws. Nine Barrels of Whiskey" and "U. S. vs. Four Barrels of Whiskey."

The libel alleged that the barrels were substituted, or did contain other spirits than those tax-paid therein. The first part of the libel read as follows:

"First: That said —— doing business under the firm name of - - Co., did then and there receive and have in their possession with intent to defraud, the said nine distillers' original packages (barrels) of whiskey, which said packages had then and there contained distilled spirits other than the contents which were therein when such packages (barrels) were labeled, stamped, branded and marked by a duly appointed officer of the Internal Revenue."

As the thirteen barrels were owned and claimed by the same parties, for convenience sake, the cases were combined for trial and heard as one case.

The thirteen packages under seizure, according to the marks and brands, contained whiskey which had been produced by two reputable distillers at different periods, stored in the respective U. S. Bonded Warehouses for different periods, in order to properly age the whiskey.

Note. - It must be understood that the Government had absolutely no suspicion that the distillers had tampered with the packages. The proceedings were what are called "in rem"; that is, the stit was for the forfeiture of the packages and not a criminal action, the Government mak ing no allegation as to who changed the contents of the barrels.

For several years the Division of Chemistry of the Bureau of Internal Revenue had been collecting analytical data on whiskey, in order to see if the chemical experts of the office were justified in deciding that a package of whiskey found on the market was not the identical whiskey indicated by the marks and brands. The method of procedure was as follows:

Upon the receipt, in the laboratory, of the sample of whiskey suspected by a Revenue officer of being other spirits than those indicated by the marks and brands on the package, orders would be sent to the Government officer at the bonded warehouse of the distillery, whose marks and brands were on the suspected package, to obtain from the bonded warehouse one or two samples as near as possible to the same date of inspection as the suspected sample.

The suspected and genuine would then be analyzed and the comparison of the different chemical constituents made. If the results were fairly close the sample was reported as genuine: if there was a marked 
discrepancy the sample was reported as containing other spirits than those tax-paid therein.

A large number of samples whose history was known were analyzed in the Bureau, a careful study made of the results, convincing the officials that a comparison could be made between packages of whiskey produced by the same distillery under approximately the same conditions of manufacture, storage and of age.

As the cases in suit were the first of their kind, and would, if decided favorably, be of great importance to the Government, it was decided to spare no expense or effort in developing unmistakably the truth or falsity of these conclusions. Instructions were therefore issued to the revenue officers, in whose districts the two distilleries were situated, to obtain a series of samples representing each year of the eight years of storage, about five for each year. To obtain the five samples as near as possible to the same date of inspection, and at least three samples of goods not more than a few days old but representing the production of different days.

The officers were told to select for the years in which the suspected samples were produced packages as near as possible to the date of inspection of the suspected samples. This was the only specific instruction to the officers as to particular packages.

This series of samples was desired for the following reasons:

The three samples of new goods to show that there was practically no difference in the analytical data between samples produced from different mashes and different dates of production when first distilled.

The five samples of each year as near as possible to the same date of inspection because such packages would, as a rule, have been stored under identically the same conditions, and, therefore, the differences due to the individual container (barrel) could be clearly shown if such existed.

The samples from each year to show the change in the different constituents, due to the length of storage.

No samples were obtained from packages but one year old as the data from these would have no real bearing on the case, all of the suspected samples having been from packages purporting to contain well matured whiskey.

The genuine and suspected samples were subjected by the same analyst; at the same time, to the following examination:

Proof determined by the regular Internal Revenue hydrometer $\left(2^{\circ}\right.$ of proof representing I per cent. of alcohol by volume at $60^{\circ} \mathrm{F}$.):

Solids.-50 cc. of whiskey were evaporated to dryness on the water bath, in platinum, dried for one hour at $100^{\circ} \mathrm{C}$. and weighed.

Color.-Determination in Lovibond's tintometer using the Brewer's scale. The results were calculated to a one-half inch cell.

Acids, Etc.-The methods for the determination of acidity, ethereal salts or esters, aldehydes, furfural and higher alcohols were such as given in Bulletin 107, revised, Bureau of Chemistry, Department of
Agriculture, in the chapter or "Analyses of Distilled Spirits," pages $95^{-6-7}$ and 8 , the Allen Marquarde method being used or the determination of the higher alcohols, results being expressed as amyl alcohol.

Color Insoluble in Water.-Color insoluble in water was determined by taking $50 \mathrm{cc}$. of the whiskey, evaporating to dryness, taking up the evaporated portion in Io cc. of hot water, filtering, thoroughly washing the paper, bringing to the $25 \mathrm{cc}$. mark with water, adding sufficient alcohol to reach the $50 \mathrm{cc}$. mark or original volume. The color of this solution was then read in a Schreiner colorimeter against the untreated whiskey, the result being reported. as the per cent. of color insoluble in water, a genuine whiskey seldom reading less than $7 \circ$ per cent.

Color Soluble in Amyl Alcohol.-It was determined by shaking the original whiskey with amyl alcohol and estimating color dissolved in this menstruum. In the genuine whiskey the per cent. of color soluble in amyl alcohol seldom falls below 70 per cent. (the Marsh test using phosphoric acid in the amyl alcohol gives readings in excess of 90 per cent.; this test, however, was not used on these samples).

Qualitative Color Tests, Chloroform Test.-About $5 \mathrm{cc}$. of the whiskey were shaken with $5 \mathrm{cc}$. of chloroform, the major portion of the natural color being dissolved by the chloroform, artificial colors, such as burnt sugar or aniline dyes, appearing in the upper layers.

Amyl Alcohol Test.-About $5 \mathrm{cc}$. of the whiskey are shaken with $2 \mathrm{cc}$. of water and $3 \mathrm{cc}$. of amyl alcohol, the amyl alcohol dissolving the major portion of the natural color, artificial colors appearing in the watery or lower layer.

Paraldehyde Test.-The Amthor test as modified by Lasche, see description, page ror, of Bulletin ro7, revised, for caramel.

On the accompanying sheets of analyses the results as obtained on the original samples are given. In parallel columns are also given these results calculated to roo proof, in this way affording an equitable basis for comparing the chemical data on each sample regardless of its real proof.

The composition of the mash, as stated, is taken from official distillery records.

The serial number of the package is the number given each package, at the particular distillery, when it is inspected.

The date of inspection is the date when the package is gauged and entered in the warehouse; this is generally the day following the final distillation.

The age, by years and months, is the time elapsed between the date of inspection and the date of taking the sample, samples having been placed in glass (careful tests have proved that spirits do not change appreciably when kept in glass bottles securely stoppered); this is, therefore, the age in wood.

The degree of color soluble in amyl alcohol, column 23 , in analytical table, is obtained by multiplying the depth of color, column ro, by the per cent. of color soluble in amyl alcohol, column 22 . 


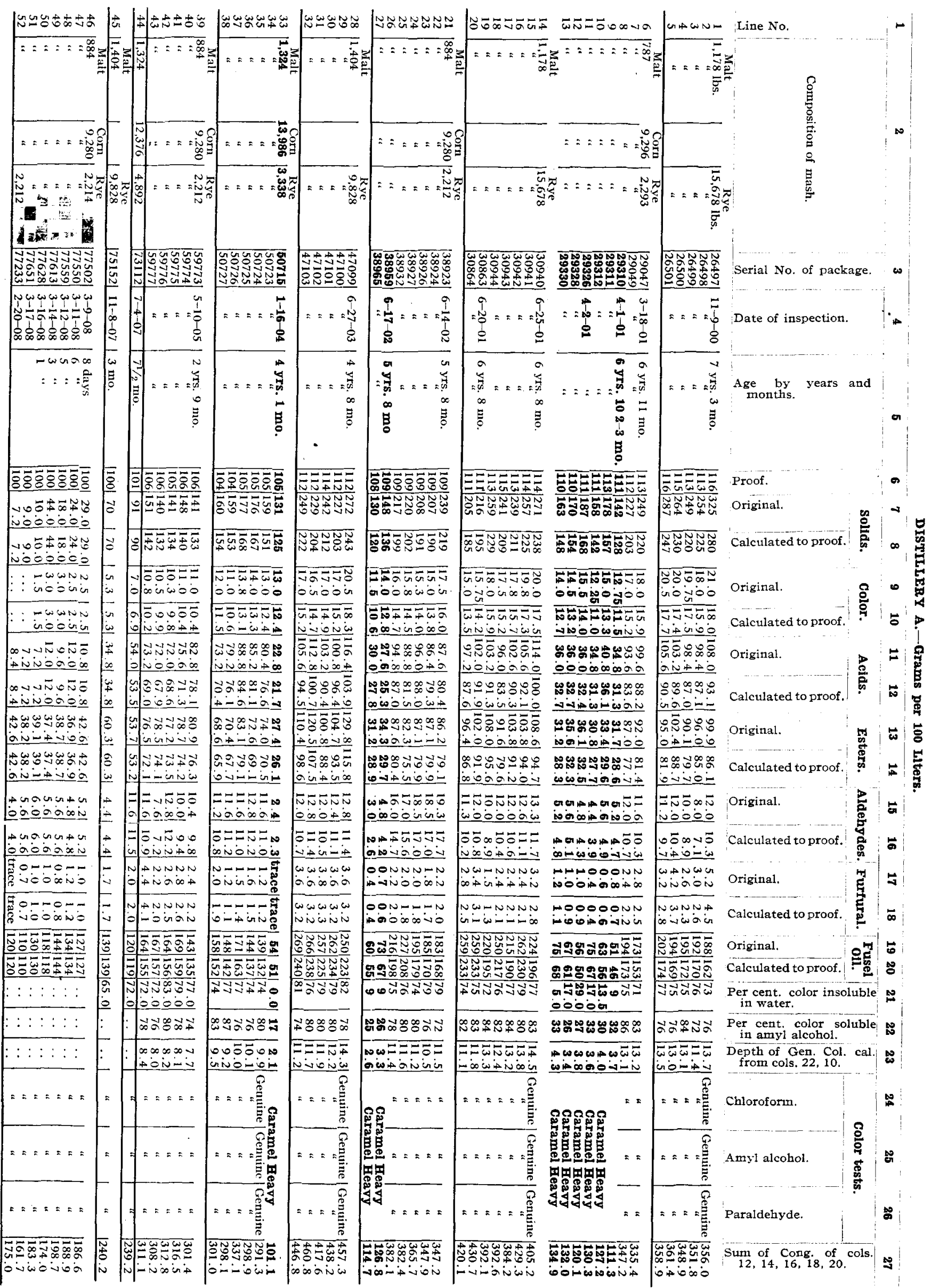


In the last column of the analytical sheet is recorded the sum of the congeneric substances.

The data for the samples taken from the packages in suit, or as they will be spoken of from now on, the suspected samples, is printed in heavy type.

The data for the samples taken from packages in the U. S. bonded warehouses of the respective distilleries, and, therefore, authentic samples, which will be spoken of as genuine samples, is recorded in light type.

The experimental work in this office had proved the following point: that when whiskey is stored in charred oak barrels in dry storage, the proof, solids, color and the different congeneric substances increase in proportion to the time stored. While this basic principle was admitted by nearly every one interested, it was contended by the attorneys for the wholesale liquor dealers, before mentioned, that while the increase was proportional to the time stored, yet there was no relation between the increase in different packages of the same age, or any age. In other words, their claim was that while these constants did increase, yet the increase was not regular, and because one package four years old contained certain amounts of acids, esters, etc., another package of the same age would contain entirely different proportions and amounts of acids, esters, etc.

An examination, by the writer, of the two distilleries whose marks and brands were on the packages under seizure showed that at that time, Fall of I 908 , every effort was being made to produce a clean new whiskey; that this was reduced to proof and bonded in charred white oak barrels of the best cooperage obtainable; that the usual warehouse care was given the whiskey the moment it was placed in the warehouse; that the warehouses were subjected to a normal temperature of from $70^{\circ}$ to $80^{\circ} \mathrm{F}$; that the aim of the distillers, in each case, was to produce a whiskey commercially as near as possible to their own standard.

Samples from Distillery " $A$ " are divided into nine groups, representing whiskey of different ages. The suspected samples are placed in the group where they belong according to the age indicated by the marks and brands.

In the group which is four years and one month old we were fortunate in obtaining five samples which were inspected the same date as one of the suspected samples, namely, package No. 50,7 I5, and, therefore, the contents of these packages were taken from the same cistern on the date they were inspected, and on that date, if the contents of the cistern had been thoroughly mixed, the whiskey in each package had identically the same composition as each and every other package. As the proof in each package was the same, the contents of the cistern had been thoroughly mixed, otherwise the proof would have varied.

Taking the packages of new whiskey we find a trace of solid matter, no color, a very small amount of acids, a larger quantity of esters, a small amount of aldehydes, practically only a trace of furfural and a considerable amount of higher alcohols. Between the two samples produced on different days and nearly a month apart there was no appreciable difference in any of the constants, the sum of the congenerics being I 6 I.7 for one, I 75.0 for the other.

In the sample one day old (which means one day in wood) we find no distinction between this and the samples just produced, except that the package one day in wood contained an appreciable amount of color.

In the sample three days old we find the solids to have increased several times more than in the samples just produced, the color is twice as much as in the sample one day in wood, the other constituents are approximately the same, a constant amount of furfural appearing in each sample (entirely due to the fact that furfural is largely extracted from the charred oak package).

The remaining samples of the new goods, namely, those of five, six and eight days old bear the same relation as the samples just discussed, an appreciable increase in the solids, color and furfural, the other constants remaining the same. The minimum amount of congenerics for this group is $16 \mathrm{r} .7$, maximum I 98.7 .

In addition to these a sample three months, and one seven and a half months old were taken; these admirably assisted in showing the process of aging. The solids have increased to 70 and 90 parts; the color to 5.3 and 6.9 degrees; the acids have changed to 34.8 parts for the three-month sample and 53.5 for the seven and a half months. The esters have increased to 60.3 and 53.2 , the aldehydes to II.5, the furfural showing a steady increase over the very new goods. The higher alcohols are approximately the same as when first produced. The total sum of the congenerics is 240.2 and 239.2 , an appreciable increase over the new goods.

These results prove: first, the uniform content of the different determinable constituents in whiskey just distilled: second, with the exception of the higher alcohols the congenerics immediately begin to show an increase.

The next group of samples is two years and nine months old. Considerable time having elapsed, decided increases would be expected. The proof has increased to 105 and 106 , four of the samples being Io6 and one I05. The solids have increased to I32 minimum and $\mathrm{r}_{42}$ maximum, the color increased to a very appreciable degree, namely, 9.8 minimum and 10.4 maximum. The acids 67.9 minimum and 78. I maximum, a difference between the five samples of only 10.2. The esters to 72.1 minimum and 76.3 maximum, a difference of $\mathbf{4 . 2}$. The aldehydes $\mathbf{7 . 2}$ minimum and 12.2 maximum; furfural 2.0 minimum and 4.I maximum; higher alcohols 135 minimum and 159 maximum, a difference of 24 . The total sum of the congenerics is 301.4 minimum and $3 \pm 6.5$ maximum, a difference of I5.I.

For the five samples the percentage of color insoluble in water ranges from 72 per cent. to 83 per cent. Depth of color soluble in amyl alcohol, calculated to Brewer's Scale, varies from $7.7^{\circ}$ to $8.4^{\circ}$. The quantitative tests for color gave positive reaction for genuine 
color, that is, there was no apparent trace of caramel or other color than that extracted from the barrels.

In the group just discussed an important change is noted, namely, an equilibrium seems to be established between the acids and the esters, it will be observed that this condition is maintained to the end of the bonded period.

The proportion between the aldehydes is fairly constant although tending to show that in some cases the influence of the package is stronger than the influence of the storage, as indicated in the one case of the aldehydes dropping to 7.2 . The furfural in one package increased to $4 . I$ as against an average of the four packagres of 2.I. It would be expected that the amount of this constant would depend upon the package, more so than upon the storage, and, that while there would be shown a general increase and ratio between the different packages, yet the maximum and minimum would vary considerably, due to the fact that the content of furfural in the charred package varies.

The next group of samples consist of six, each bearing inspection marks of the r6th of January, I004. Five of these samples, namely, 50,723-27 inclusive, were taken from the respective packages at the $U$. S. Bonded Warehouses, and were four years and one month old when taken. Sample package No. 50,7 I5 was taken from a package on the premises of the claimant of the litigation. As was mentioned previously, all packages. inspected on the same day are necessarily taken from the same cistern which has been thoroughly mixed and reduced to the proper proof before a single package is filled. On this day, namely, Tanuary I6, I 904 , the contents of each and every package inspected would have analyzed the same, as each was an aliquot portion of the cistern.

Four of the six samples have a proof of $1_{5}$ and two a proof of I04. The solid content of the genuine samples varies from I5I to 168 ; the solid content of the suspected sample is 125 . The depth of color in the genuine varies from 10.6 to 13.3 ; the color of the suspected sample is 12.4 . (It is expected that in these cases when substitution has been effected, that artificial color will be added and the depth of color brought back to that of the original whiskey, at least.)

The acids of the genuine samples analyzed vary from 70.4 to 84.6 , a difference of 14.2 ; the acids of the suspected samples 21.7 , or about 48.7 points less than the minimum sample of the genuine.

The esters of the genuine vary from 65.9 to $79 . \mathbf{x}$, a difference of $\mathrm{r}_{3.2}$; the esters of the suspected sample are 26 . I or 39.8 less than the minimum genuine.

The aldehydes of the genuine vary from 10.8 to I 2.2; the suspected sample contains 2.3 parts.

The furfural of the genuine varies from I.I to I.9; only a trace of furfural appears in the suspected.

The content of higher alcohols, of the genuine samples, varies from $I_{32}$ to $I_{3}$, a difference of $3 \mathrm{I}$; the content of the suspected samples in higher alcohol is $5 \mathrm{I}$ parts, or $8 \mathrm{I}$ parts less than the minimum genuine.

The claim is made that as the higher alcohol content of these six packages on the day of inspection was the same, and any difference at the time of the analysis was due to evaporation and osmotic action which changes tend to increase the higher alcohol content and never diminishes it, then these results clearly show that package 50,7 I5 contained only about one-third of the fusel oil that should be expected.

In studying the composition of the color, we find that the "color insoluble in water" of the genuine samples varies from 74 to 77 per cent.; there is no color insoluble in water in the suspected samples; all of the color dissolving in this menstruum.

The "color soluble in amyl alcohol" for the genuine varies from 76 to 87 per cent. The same test on the suspected shows only i 7 per cent soluble. The depth of color soluble in amyl alcohol varies from 9.2 to 10.I; the depth of color soluble in amyl alcohol of the suspected sample is 2.I. The qualitative test for artificial coloring matter proved the color of the genuine samples to be genuine color, derived from the oak package; the same tests on the suspected samples proved a heavy artificial coloration.

The sum of the congeneric substances in the genuine samples vary from $29 \mathrm{I.3}$ to $337 . \mathrm{I}$, a difference of 45.8 between the maximum and minimum, or samples taken from packages known to be unsophisticated; the sum of the congenerics in the suspected sample is IOI.I, or only one-third as much as the genuine samples.

The next group of samples analyzed are five samples taken from packages four years and eight months old, on the premises of the U. S. Bonded Warehouse. The proof in four of the samples is II2, in one II 4. The solids vary from 204 to 243 . The color from I 4.9 to I8.3. The acids from 90.4 to I03.O. The esters from 88.4 to I 5.8 . The aldehydes from 10.5 to II.4. Furfural 3.2 to 3.3. Higher alcohol 225 to 224. The color insoluble in water 76 to 82 per cent. Color soluble in amyl alcohol 74 to 80 per cent. The depth of color soluble in amyl alcohol II. $2^{\circ}$ to $14.3^{\circ}$. The qualitative tests for color proved in each case to be genuine. The sum of the congeneric substances varies from $4 \mathrm{I} 7.6$ to 460.8 .

The next group of samples analyzed contains whiskey five years and eight months old. Five samples inspected 6-I4-O2, taken from U. S. Bonded Warehouses; two samples, namely, 38,959 and 38,965 , inspected three days after the samples just mentioned were taken from packages found on the premises of the claimant of the whiskey, being two of the packages in litigation. The proof of the genuine sample is I०9; of the suspected samples Io9 and $\mathrm{\circ} \circ 8$ respectively. The solid contents of the genuine samples vary from I 90 to 2 Ig; of the suspected samples I 20 and I 36 . The depth of color of the genuine varies from 13.8 to 16 ; of the suspected 12.8 and Io.6. The acids of the genuine vary from 79.3 to 88.0 ; of the suspected 25.3 to 27.8 . The esters on the genuine vary from 75.5 to 90.4 ; of the suspected 29.7 and 28.9 . The aldehydes of the genuine vary from I 4.7 to $I 7$; in the suspected 4.2 and 2.6. Furfural from 1.8 to 2.2 in the genuine, and in the suspected 0.6 and 0.4 . The 
fusel oil found in each genuine sample varies from I68 to 208 , and in the suspected samples 67 and 55 , or about one-third of that amount found in the whiskey known to be genuine.

Examining the composition of the color we find that the color insoluble in water in the gentuine varies from 74 to 79 per cent., on the suspected it is 90 per cent. In each case the color soluble in amyl alcohol, in the genuine, varies from 72 to 80 per cent.; in the suspected samples 26 and 25 per. cent. is soluble. The depth of color soluble in amyl alcohol, in the genuine, varies from I0.5 to Ir.6; in the suspected it is 3.3 and 2.6. Qualitative tests for color in the genuine prove all the color to be that extracted from the oak packages. The same tests show a heavy artificial coloration in the suspected packages.

The sum of the congenerics in the genuine varies from 347.2 to 382.4 , a difference of 35.2 . The sum of congenerics of the suspected samples is $x 26.8$ and II 4.7 or 220 points less than in the genuine package containing the smallest amount.

The next group of samples analyzed consists of fifteen samples, nine taken from the Bonded Warehouse, and six from packages found on the premises of the claimants, and therefore part of the packages in litigation.

The samples vary in age from six years and eight months to six years and eleven months.

The proof in the gentine samples varies from III to II 5 ; in the suspected from IIO to II 3 . The solids of the genuine vary from 185 minimum to 238 maximum; the suspected from I 28 to I68. The depth of color of the genuine from 13.5 to 17.5 ; suspected Ir.O to I4.O. The acids of the genuine vary from 83.6 minimum to roo.0 maximum; of the suspected from 34.8 to 40.8 . The esters from 77.7 to 95.6 , while the esters of the suspected from 27.7 to 32.5 , or about one-third as high as the genuine samples of the same age. The aldehydes from to to 13.3 ; the suspected aldehyde content from 3.9 to $5 . x$. The furfurals varied from I.3 to 3.1 ; the suspectepd from 0.4 to I.I. The higher alcohols of the genuine from I53 to 233 ; in the suspected from 46 to 68 , about one-third as high as the content of the authentic samples.

The color insoluble in water of the genuine from 72 to 79 per cent.; of the suspected 5.0 to 29 per cent. The color soluble in amyl alcohol from 80 to 86 per cent.; in the suspected from 26 to 33 per cent. The depth of color soluble in amyl alcohol from $\mathrm{II.x}{ }^{\circ}$ to I $4.5^{\circ}$ for the genuine, 3.4 to 4.0 for the suspected. The qualitative tests proved no artificial color in the genuine samples, while a large amount of caramel was indicated as present in the suspected.

The sum of the congenerics of the genuine vary from 335.4 to 430.7 ; the suspected from III.3 to I34.9, or the same difference as indicated in the other comparisons.

The last group analyzed consisted of five samples seven years and three months old in wood.

The proof varies from in 3 to II6. The solids from 220 to 280 . The depth of color from I5.9 to 18 .
The acids from 87.0 to 93.I. The esters from 79.7 to 88.7. The aldehydes from 7.I to I0.4: The furfurals from 2.3 to 4.5 . The higher alcohols from $i 62$ to 174 . The color insoluble in water 73 to 77 per cent. The color soluble in amyl alcohol from 72 to 84 per cent. The depth of color soluble in amyl alcohol from II.4 to I 3.7. The sum of the congenerics from 348.9 to 36 I. 4 .

A careful examination of this résumé of the tables and the curves should convince one of the following points concerning the whiskey taken from the U. S. Bonded Warehouse and described herein as genuine:

I. That there is a general tendency in the proof, color, solids, and the congenerics to increase the longer the storage.

2. That the results prove this increase to be uniform and comparable in packages of approximately. the same age, the variation being almost negligible, when taking into consideration the possible variation between two different determinations.

3. That the individual package seems to have no other influence (in this connection) than to cause a slight variation in the depth of color and the amount of aldehydes. The content of furfural depends almost entirely on the package and the length of storage.

4. The composition of the color extracted is the same in all the packages, never less than 70 per cent. insoluble in water, or the same per cent, soluble in amyl alcohol (note about Marsh test).

As regards the suspected samples they are not similar to the genuine samples in any points, except proof and depth of color.

The following is the examination of a so-called "Neutra1" spirit, or "Blending Goods:"

\begin{tabular}{|c|c|c|}
\hline & \multicolumn{2}{|c|}{$\begin{array}{c}\text { Grams per } \\
100 \text { liters. }\end{array}$} \\
\hline & Acids. & 13.3 \\
\hline Proof, 100 per cent. & Esters .... & 20.4 \\
\hline Color, water white...$\ldots$ & Higher alcohols . . . . & 6.3 \\
\hline Odor, neutral... & Aldehydes... & 0.5 \\
\hline & Furfural ......... & 0.0 \\
\hline
\end{tabular}

This is the class of goods frequently used in this kind of manipulation (substitution) and if used in the proportion of two parts of neutral spirits to one of the real whiskey, brought to the proper degree of proof and colored with caramel, until the deficiency in the color, caused by the water white spirit is made up, will give upon analysis figures very similar to the whiskey called suspected herein.

I will not consider in such detail the analysis of the whiskey taken from the distillery designated herein as Distillery " $B$," and of the four packages in litigation bearing marks and brands of this distillery, but suspected of containing other spirits.

These packages were proceeded against in order to introduce evidence in the analytical data of samples from another distillery located in another section of the country where different local conditions might exist. In this case the whiskey in litigation was supposed to be eight years and ten months old, or ten months older than the law permits whiskey to remain in bond; thus it was impossible to obtain samples from the warehouse nearer than ten months 
Sept., IgII THE JOURNAL OF INDUSTRIAL AND ENGINEERING CHEMISTRY.

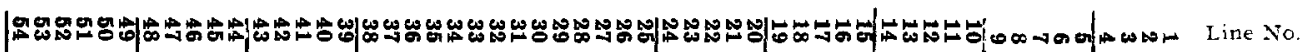

\begin{tabular}{|c|c|c|c|c|c|c|c|}
\hline 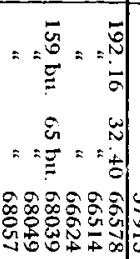 & $\therefore=\therefore=0$ & 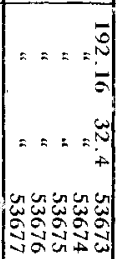 & 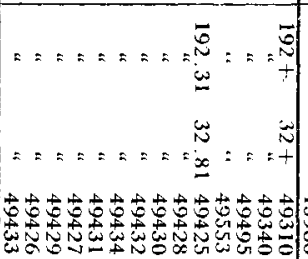 & 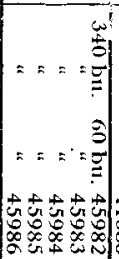 & 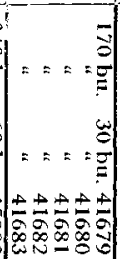 & 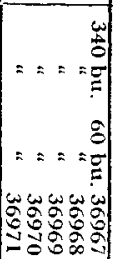 & 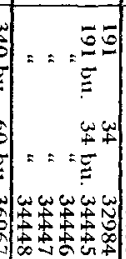 \\
\hline 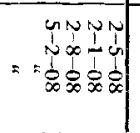 & $=2=0 \frac{7}{3}$ & & 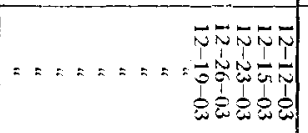 & & & 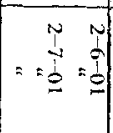 & 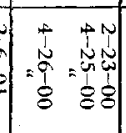 \\
\hline $\sin \bar{\omega} \alpha_{\infty}$ & & & 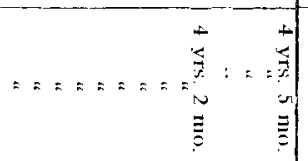 & & & & 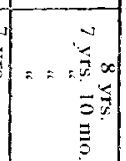 \\
\hline
\end{tabular}

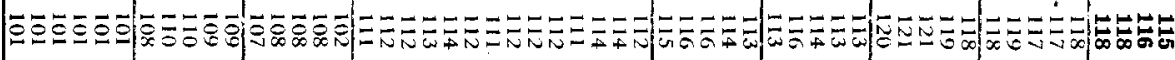

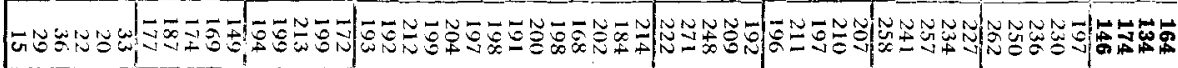

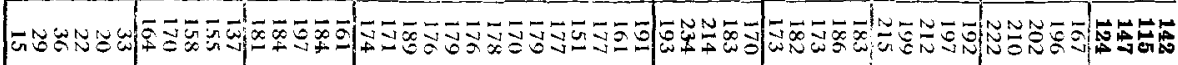

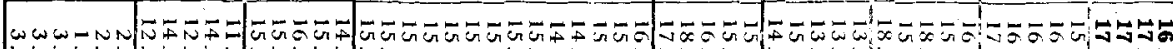

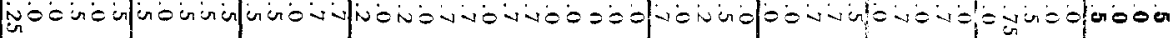

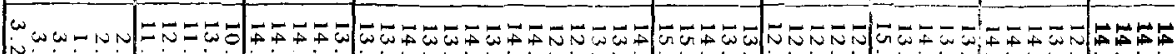

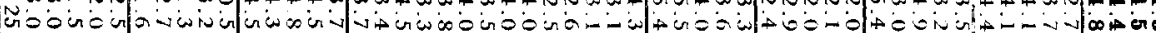

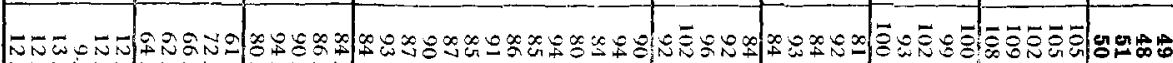

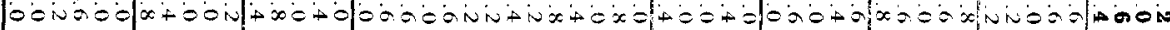

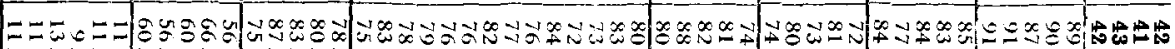

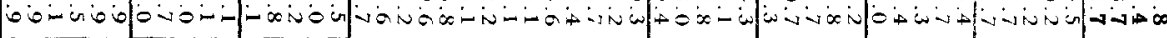

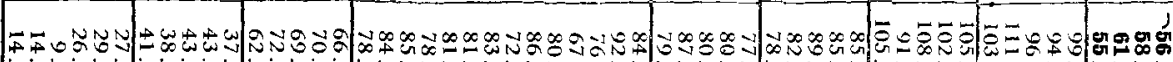

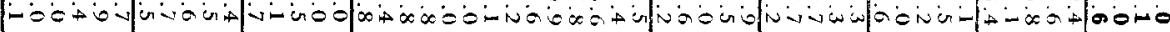

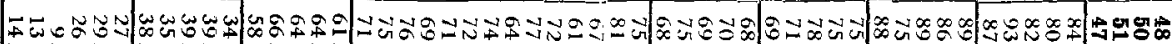

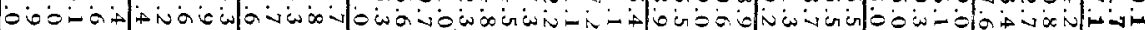

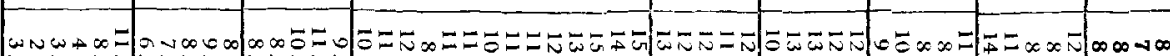

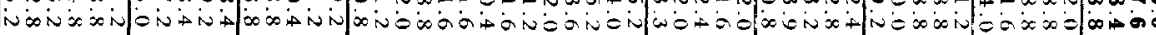

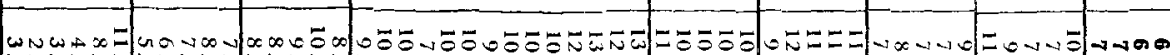

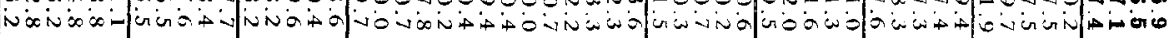

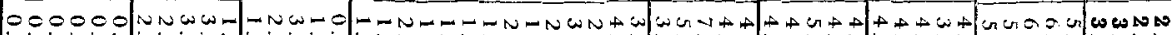

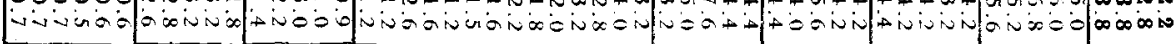

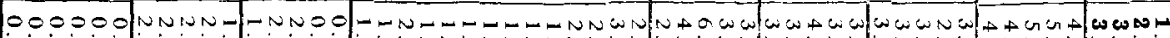

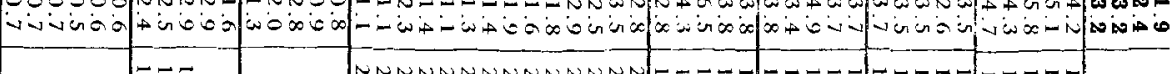

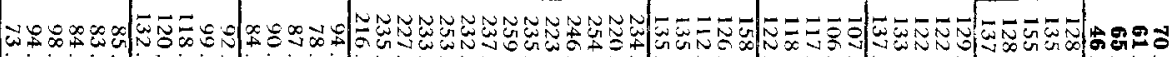

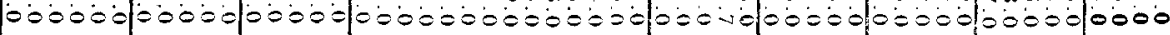

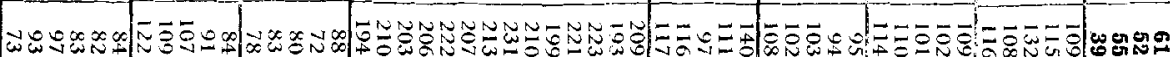
$0000000000000000|00000000000000| 0=00000000100=000000010000$

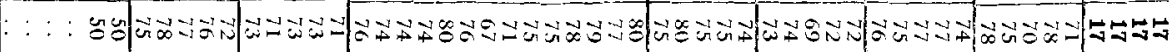

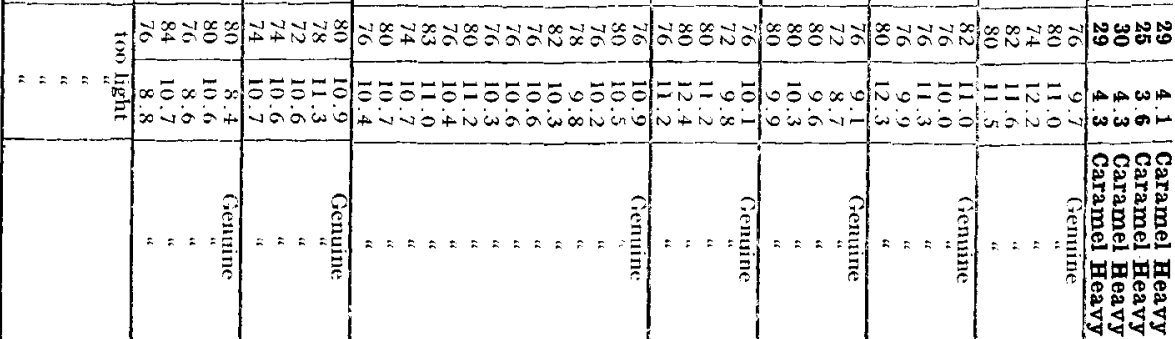

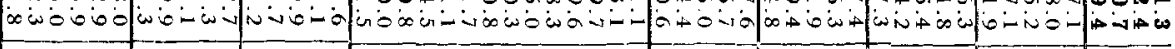

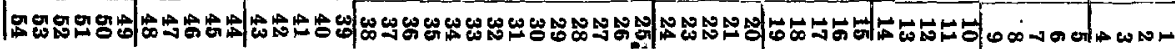

Age by years and on
months. Proof Original. Calculated to proof Original a Calculated to proof. Original.

Original.

Calculated to proof

Original.

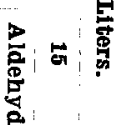

Calculated to proof.

Original.

Calculated to proo

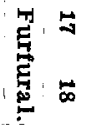

Original.

Calculated to proof

Per cent. color insolitPer cent. color soluble in"annyl alcohol. Depth of Gen. Col. cal. from cols. 22, Chloroform

Amyl alcohol

Paraldehyde.

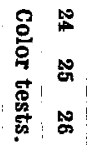
Sum of Cong. sub. columns $12,14,16=$

Line No. 
or a year; the proposition, therefore, evolved itself into proving that the product of this distillery when aged in its own warehouse contained certain amounts of color, solids and the different congenerics, and that the contents of one package were comparable chemically to the contents of another package of approximately the same age.

A careful perusal of the analytical table and the curves proves essentially the same points as for Distillery "A." One marked variation developed, namely, in the higher alcohol content in the samples produced during the Fall of 1903 , when nearly twice as much
A comparison of the suspected and the genuine will prove that the spirits in the four packages are not similar to the genuine and younger goods analyzed. The content of acids in the suspected is less than in the two-year goods. The content of esters less than in the three-year goods. The higher alcohols are less than for even the new goods.

All comparison ceases here and the differences become more glaring the older the whiskey becomes.

In conclusion it should be stated that in work of this kind, the acids, esters and color form the points which should be used to determine the authenticity of

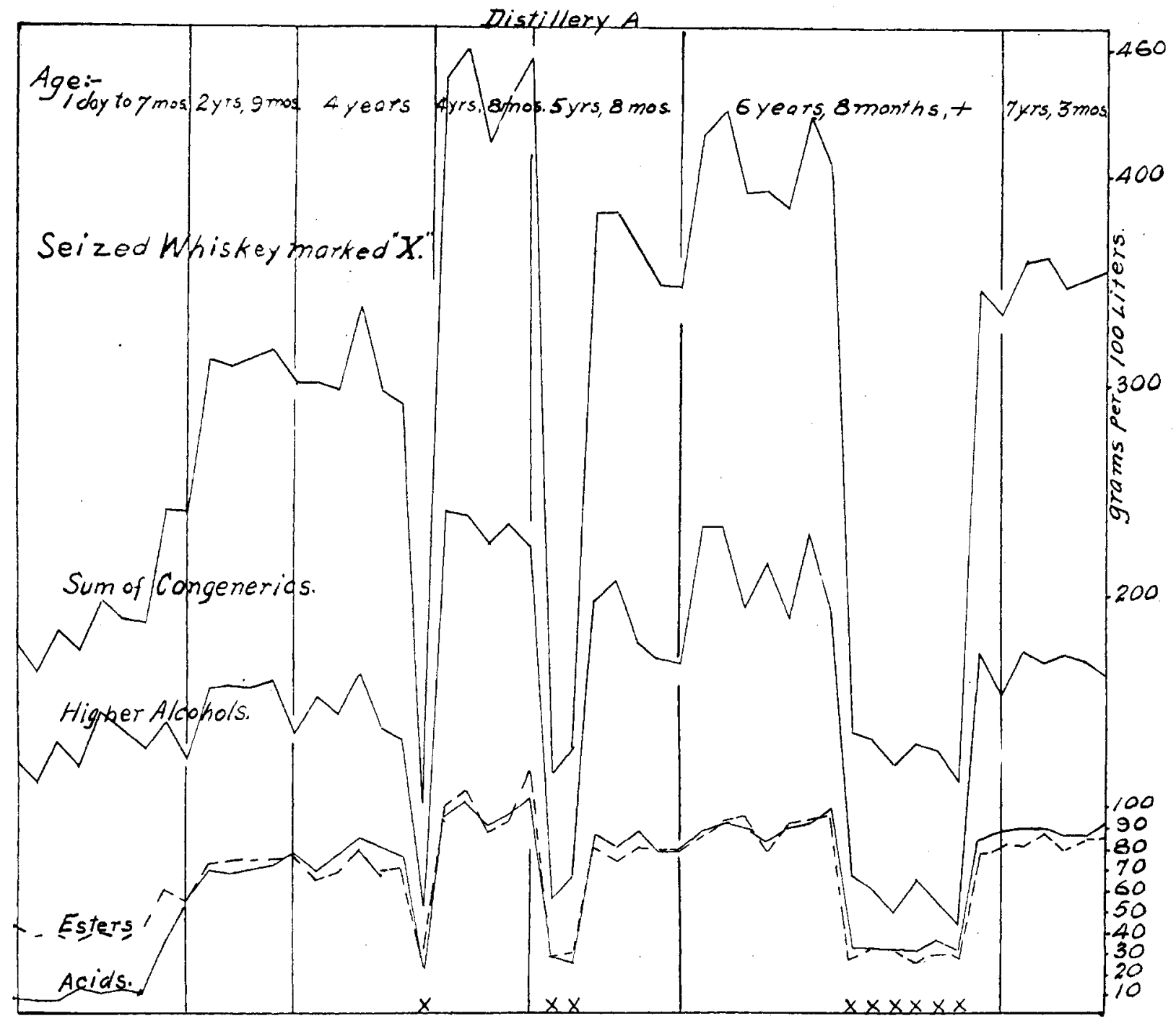

higher alcohols were produced as at any other period. (The distiller, Mr. - - suggested that as the rye was of poor quality that year, this might account for the high amount. I am inclined to think his suggestion is a good one.) This exception, of course, is repeated in the sum of the congenerics. This result would tend to show that while storage has an effect on the quantity of the higher alcohols (they increasing by concentration), yet the amount present depends more on the fermentation and the method of distillation. the contents of a package of whiskey. The content of solids, higher alcohols, aldehydes and furfural will assist in arriving at a conclusion, but should not be relied upon solely, as can be done in the case of the acids, esters and color.

HISTORY OF THE CASE.

Trial began April 6, rgog, and ended April I 4, I 909.

Jury returned verdict for the Government deciding that the packages did contain other spirits than those tax-paid therein. 


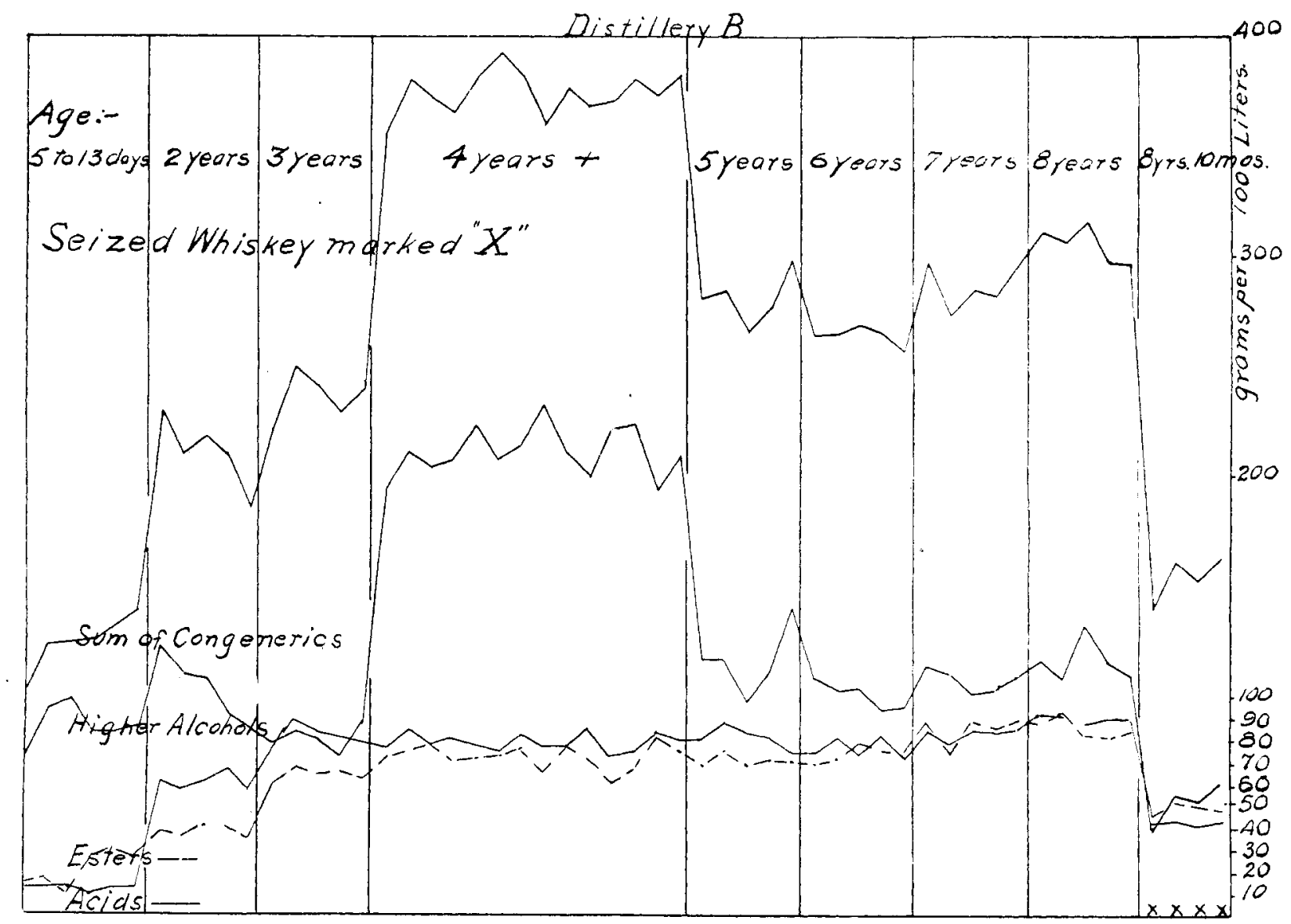

Submitted to Circuit Court of Appeals, June I5, I 9 Io, decided by Circuit Court of Appeals, July I3, I9I0. Reported in "Federal Reporter," Vol. I8I, pages $296-306$.

The Higher Court decided that:

"We are satisfied that under the evidence the jury was warranted in finding that the nine barrels in question contained distilled spirits other than the contents which were in them when they were lawfully stamped, etc................ if the testimony offered by the Government is competent." Further on in the opinion: "We conclude that the conditions under which the contents of the seized barrels and the contents of the barrels taken for comparison were produced and hardled were sufficiently similar to justify the admission of the evidence objected to."

The case was remanded for a new trial as the Government did not prove that the claimants received the packages in the illegal condition as stated in the libel. The case will not be retried, the Government having obtained a favorable decision on the two main points at issue, namely:

I. Can the presence of other spirits in a package of double stamped whiskey be proven by chemical analysis?

2. Are the analyses of samples taken from packages in the same warehouse proper evidence against similar whiskey under seizure?
THE RELATION OF NITRATE OF SODA TO THE MECHANICAL CONDITION OF COMMERCIAL FERTILIZERS. ${ }^{1}$

\section{By JACOB G. LIPMAN.}

Received May 1, 1911.

The increasing cost of organic ammoniates and the inert character of a considerable proportion of the materials (used in the making up of commercial mixtures) are forcing progressive farmers to resort, more and more, to home mixing. Those who have learned to use purchased plant food with discretion have realized that the better sources of animal and vegetable nitrogenous substances like dried blood, concentrated tankage, dried and ground fish, and cottonseed-meal have become economic luxuries. But, expensive as are these so-called high-grade materials as a source of nitrogen to crops, they are cheap as measured against the lower grades of tankage, dried blood, and, more particularly, of garbage tankage, leather scrap, hair and wool waste and peat.

It is a fact, indisputably established by almost innumerable experiments and observations, that different materials used as sources of nitrogen to crops vary in their availability. Otherwise, stated, some of these substances furnish a large part of their nitrogen to growing crops; that is, they are readily available, while others yield up but a small portion of their nitrogen within one or two growing seasons; that is, they are slightly available. The question of the rela-

\footnotetext{
I Laboratory New Jersey Agricultural Experiment Station.
} 